\title{
DÜBLIN
}

Technological University Dublin

ARROW@TU Dublin

2014-10-23

\section{Spatial Skills as Predictors of Success in First-year Engineering}

\author{
Sheryl Sorby \\ Michigan Technological University, sheryl@mtu.edu \\ Edmund Nevin \\ Technological University Dublin, edmund.nevin@tudublin.ie \\ Avril Behan \\ Technological University Dublin, avril.behan@tudublin.ie
}

See next page for additional authors

Follow this and additional works at: https://arrow.tudublin.ie/engschcivcon

Part of the Educational Methods Commons, Engineering Commons, and the Higher Education

Commons

\section{Recommended Citation}

Sorby, S., Nevin, E., Behan, A., Mageean, E. and Sheridan, S. (2014). Spatial Skills as Predictors of Success in First-year Engineering. In Proceedings 44th Annual Frontiers in Education (FIE) Conference, pp. 111-117. 22-25 October. Madrid, Spain. doi:10.1109/FIE.2014.7044005

This Conference Paper is brought to you for free and open access by the School of Civil and Structural Engineering at ARROW@TU Dublin. It has been accepted for inclusion in Conference papers by an authorized administrator of ARROW@TU Dublin. For more information, please contact arrow.admin@tudublin.ie, aisling.coyne@tudublin.ie,gerard.connolly@tudublin.ie.

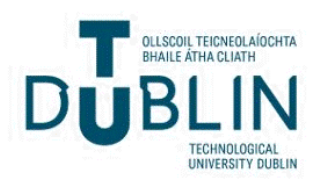




\section{Authors}

Sheryl Sorby, Edmund Nevin, Avril Behan, Eileen Mageean, and Sarah Sheridan

This conference paper is available at ARROW@TU Dublin: https://arrow.tudublin.ie/engschcivcon/64 


\title{
Spatial Skills as Predictors of Success in First-year Engineering
}

\author{
S. Sorby ${ }^{1}$, E. Nevin ${ }^{2}$, A. Behan ${ }^{3}$, E. Mageean ${ }^{4}, \&$ S. Sheridan ${ }^{5}$ \\ CREATE Research Group \\ College of Engineering and the Built Environment \\ Dublin Institute of Technology \\ Ireland \\ 1'sheryl@mtu.edu; ${ }^{2}$ edmund.nevin@dit.ie; ${ }^{3}$ avril.behan@dit.ie; ${ }^{4}$ eileen.mageean@dit.ie; ${ }^{5}$ sarah.sheridan@dit.ie
}

\begin{abstract}
Numerous research studies have highlighted the importance of well-developed 3-D spatial skills for success in STEM related programs. Poor spatial skills, particularly among first-year students, can place them at a distinct disadvantage when completing introductory courses in mathematics, CAD, descriptive geometry, and graphic communications - first-year requirements in many $S T E M$ related programs. This in turn can lead to poor grades and retention issues. Women are disproportionally among the group of students with weak or poorly developed 3-D spatial skills meaning that they are at a greater risk of leaving engineering when compared to their male counterparts. In this study, the spatial skills of first-year students in several engineering and technology programs were assessed through two standardized instruments widely used in spatial cognition research. The spatial skills of architecture and computer science students were also assessed for comparison purposes. This paper outlines the results obtained from a study at an Institution of Higher Learning and draws conclusions regarding the importance of spatial skills for success in introductory STEM courses. Grades at the end of the semester were obtained in several mathematics courses to determine if there is a correlation between spatial skill level and student performance in introductory math courses.
\end{abstract}

Keywords—spatial skills; gender differences; student access

\section{BACKGROUND}

The ability to think spatially is a cognitive process that has been shown to be important to higher level thinking skills. The specific types of 3-D spatial skills that have been identified by psychologists include [1]:

- Spatial Perception: Ability to identify horizontal and vertical directions;

- Spatial Visualization: Ability to mentally transform (rotate, translate or mirror) or mentally alter 3-D objects;

- Mental Rotations: Ability to mentally rotate an object and then rotate a different object by the same amount;

- Spatial Relations: Ability to visualize the relationships between two objects, i.e. overlapping or nonoverlapping; and
- Spatial Orientation: Ability to mentally determine your own location within a given environment.

Research has demonstrated the high level of 3-D spatial skills found in students of engineering and architecture; however, not all of our first-year students have strong spatial skills when they start their post-secondary studies. Recent work has also shown the link between spatial skills and creativity and innovation. Several tests have been developed through the years designed to assess an individual's spatial skills in most of these areas. In this study, two specific tests were used to assess spatial skills. End of first semester grades were obtained for the students in several key courses to determine if there is a correlation between spatial skill level and student performance in introductory courses. Results obtained through this testing will be compared across disciplines and programs and will also be compared to similar data obtained from testing engineering students in the U.S.

Unfortunately, of all cognitive processes, spatial skills exhibit the most robust gender differences, favoring males [2][3]. At a time when we are striving to increase the participation of women in STEM fields, particularly engineering, poorly developed 3-D spatial skills of women may be a hindrance to their success in our programs.

\section{A. Purdue Spatial Visualisation Test; Rotations}

The first to be administered was a test of mental rotation, the Purdue Spatial Visualization Test: Rotations (PSVT:R) [4]. For the items on this test, an object is shown on the top line which has been rotated in space by a given amount. A second object is shown on the next line and the test taker must mentally rotate this second object by the same amount and choose the correct view from the third line of the problem. An example problem from the PSVT:R is illustrated in Fig. 1.

\section{B. Mental Cutting Test}

The second test of spatial visualization used in this study was the Mental Cutting Test (MCT) [5]. This test was first used as part of a college entrance exam in the U.S. in 1939 and measures a person's ability to imagine the cross-section of an object that has been sliced by an angled cutting plane. With this test an object and a cutting plane are presented on the left and 
the participant must select the correct cross-section from those given. Fig. 2 shows an example problem from the MCT.

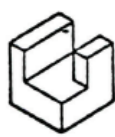

IS ROTATED TO

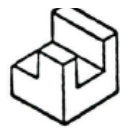

AS<smiles>C1C2CC3CC1CC(C2)C3</smiles>

IS ROTATED TO
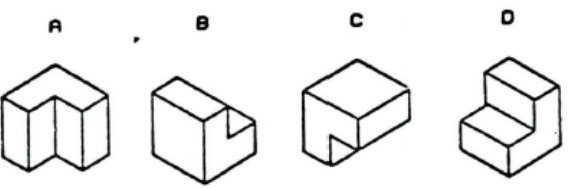

E

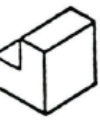

Fig. 1. Example problem from PSVT:R (correct answer = D)
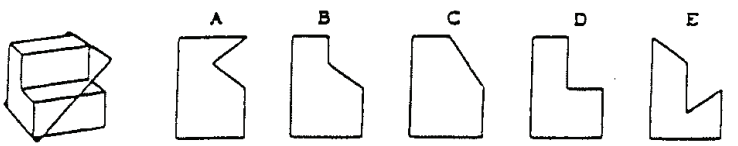

Fig. 2. Example problem from MCT $($ correct answer = D)

\section{IRISH EDUCATIONAL SYSTEM}

\section{A. Entry to third level in Ireland}

The Irish educational system consists of a four-tier structure taking in pre-school, primary, secondary and higher education sectors. Each year a large number of students progress from secondary education to continue their studies at further education centers or institutes of higher education or universities [6]. Figures from the Higher Education Authority (HEA) show a steady increase in the numbers studying STEM (Science, Technology, Engineering, and Mathematics) related disciplines [7]. The Dublin Institute of Technology is the largest Institute of Higher Education in Ireland with in excess of 22,000 undergraduate students registered in a wide variety of programs.

Entry to higher education in Ireland is based on points obtained in a senior state examination known as the Leaving Certificate (LC) which takes place at the end of their final year in secondary school. Points are counted from the students best six subjects with a maximum of 600 points available. The Central Applications Office (CAO) is the body through which applications are made for almost all of the higher education programs. A student may gain entry to a program once they have reached the minimum points level for that program in a given year. The minimum points level for a program is determined by student demand and the number of places available.

The points available per subject taken are listed in Table I. With some exceptions the majority of subjects may be taken at two levels, 'higher' and 'ordinary'. A third category known as 'foundation' level is available for a number of subjects including mathematics. Students who take the foundation level in mathematics are generally not eligible for direct entry into most institutes of higher education. In order to encourage the uptake of higher level mathematics a bonus of 25 points is given to those who sit and pass the higher level math exam irrespective of the grade achieved.

\section{B. National Framework of Qualifications}

The development and promotion of qualifications across education and training in Ireland is the responsibility of the National Qualifications Authority of Ireland (NQAI) who have developed a National Framework of Qualifications (NFQ). The primary purpose of the NFQ is to ensure that qualifications are of a quality and standard that is recognized both nationally and internationally.

TABLE I. LEAVING CERTIFICATE POINTS

\begin{tabular}{|cc|c|c|c|}
\hline \multirow{2}{*}{ Leaving Certificate Grade } & \multicolumn{3}{|c|}{ Points Awarded } \\
\cline { 3 - 5 } & $\begin{array}{c}\text { Higher } \\
\text { Paper }\end{array}$ & $\begin{array}{c}\text { Lower } \\
\text { Paper }\end{array}$ & $\begin{array}{c}\text { Foundation } \\
\text { Maths. }\end{array}$ \\
\hline A1 & $(90 \%-100 \%)$ & 100 & 60 & 20 \\
\hline A2 & $(85 \%-89 \%)$ & 90 & 50 & 15 \\
\hline B1 & $(80 \%-84 \%)$ & 85 & 45 & 10 \\
\hline B2 & $(75 \%-79 \%)$ & 80 & 40 & 5 \\
\hline B3 & $(70 \%-74 \%)$ & 75 & 35 & -- \\
\hline C1 & $(65 \%-69 \%)$ & 70 & 30 & --- \\
\hline C2 & $(60 \%-64 \%)$ & 65 & 25 & --- \\
\hline C3 & $(55 \%-59 \%)$ & 60 & 20 & --- \\
\hline D1 & $(50 \%-54 \%)$ & 55 & 15 & --- \\
\hline D2 & $(45 \%-49 \%)$ & 50 & 10 & --- \\
\hline D3 & $(40 \%-44 \%)$ & 45 & 5 & --- \\
\hline E & $(25 \%-39 \%)$ & --- & --- & --- \\
\hline F & $(10 \%-24 \%)$ & --- & --- & --- \\
\hline NG & $(0 \%-9 \%)$ & --- & --- & -- \\
\hline
\end{tabular}

A comparison between NFQ awards and the U.S. equivalent is provided in Table II. DIT offers awards from levels 6-10 of the NFQ. For entry onto level 8 engineering programs $(\mathrm{BE})$ a student requires a minimum grade of $\mathrm{C}(55 \%)$ in the higher level secondary mathematics exam. Entry to level 7 engineering programs (B. Eng. Tech.) requires a minimum of grade D $(40 \%)$ on the lower level mathematics exam. Generally speaking, students on level 8 programs will have a higher mathematical preparation than those on level 7 programs.

TABLE II. COMPARISON BETWEEN IRISH AND AMERICAN AWARDS

\begin{tabular}{|l|c|l|}
\hline \multicolumn{1}{|c|}{ NFQ Award } & $\begin{array}{c}\text { Years } \\
\text { to } \\
\text { degree }\end{array}$ & \multicolumn{1}{|c|}{ U.S. Equivalent } \\
\hline Level 6 (Higher Certificate) & 2 & Associate Degree \\
\hline Level 7 (Ordinary Bachelors Degree) & 3 & Bachelors in Eng. Tech.* \\
\hline Level 8 (Honours Bachelors Degree) & 4 & BS in Engineering \\
\hline Level 9 (Masters Degree) & $\approx 2$ & Masters Degree \\
\hline Level 10 (Doctoral Degree) & $\approx 4$ & Doctoral Degree \\
\hline
\end{tabular}

*Not exact equivalent 
The routes taken by students taking level 7 (three years) and level 8 (four years) engineering programs at DIT is illustrated in Fig. 3. Students can also take a common first-year engineering program which provides them with another access route to any of the discipline-specific level 8 engineering programs offered by DIT. This route is typically taken by students who either do not obtain the minimum grade in mathematics or who do not achieve the required points for entry onto a particular level 8 program. Also illustrated in Fig. 3 is a general entry route which provides a non-discipline specific route for level 7 applicants.

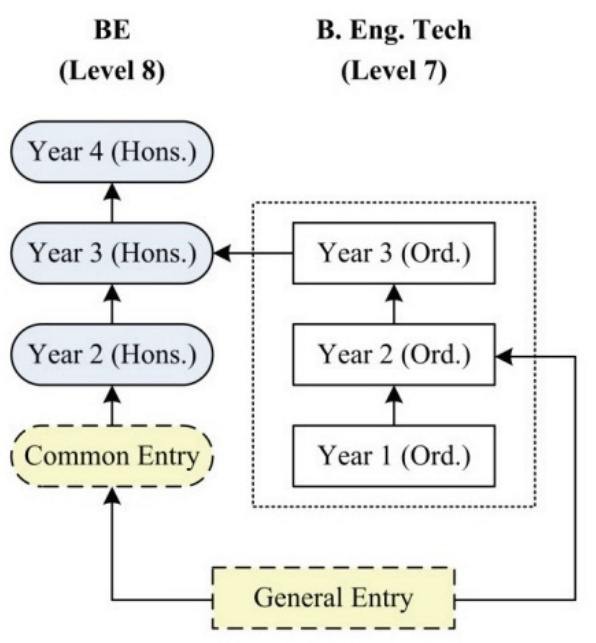

Fig. 3. Route to level 7 and level 8 engineering programs in DIT.

\section{METHOD}

The two tests of spatial cognition (the PSVT:R and MCT) were administered during regular class times for various programs at DIT during semester 1 (Fall) of the 2013-14 academic year. In the case of DT004 (level 7 Civil Engineering program), the tests were administered during the second week of semester 2 (Spring) of the academic calendar. Students were given 20 minutes to complete each test. In a few cases, both tests were administered on the same day; however, in most cases the tests were administered approximately one week apart. Thus, for several students, scores on only one of the two tests is available.

At the end of the semester, student grades in their courses were obtained on a numerical scale of $0-100$. It should be noted that in Ireland, a score of $40 \%$ is the minimum in order to receive a passing grade in the course. In this paper, we will focus on the results from three programs - level 7 engineering programs in Civil and Mechanical Engineering and the level 8 Common Engineering program. A comparison of CAO entry points for the two level 7 programs as well as the level 8 common engineering program are provided in Table III. The figures in brackets represent the mid-point entry CAO points.

TABLE III. PROGRAM ENTRY POINTS

\begin{tabular}{|c|c|c|c|}
\hline \multirow{2}{*}{$\begin{array}{c}\text { Academic } \\
\text { Year }\end{array}$} & \multicolumn{2}{|c|}{ Level 7 } & Level 8 \\
\cline { 2 - 4 } & DT004 & DT006 & DT025 \\
\hline $2012-13$ & $240(335)$ & $300(385)$ & $350(415)$ \\
\hline
\end{tabular}

\section{General Results From Spatial Skills Testing}

In all, there were more than 800 students who completed one or both of the tests. For students who had scores for both tests, the correlation between the two tests was obtained ( $r=$ $0.634, p<0.0001)$, indicating that a person's score on one test is a relatively good predictor of his/her score on the other test. The overall average for the PSVT:R was 20.46 out of a possible $30(68.2 \%)$ and 11.55 out of a possible $25(46.2 \%)$ on the MCT. These findings mirror results obtained elsewhere that indicate that the MCT is the more difficult of the two tests [2]. Gender differences for first-year students were examined, with results presented in Table IV. From this data, it is evident that there are significant gender differences on both tests favoring males. This finding is consistent with data from several previous studies [3], [8]-[10].

TABLE IV. AVERAGE SCORES FOR FIRST-YEAR STUDENTS DISAGGREGATED BY GENDER

\begin{tabular}{|c|c|c|c|c|}
\cline { 2 - 5 } \multicolumn{1}{c|}{} & \multicolumn{2}{c|}{$\begin{array}{c}\text { PSVT:R } \\
\text { (ex. 30) }\end{array}$} & \multicolumn{2}{c|}{$\begin{array}{c}\text { MCT } \\
\text { (ex. 25) }\end{array}$} \\
\cline { 2 - 5 } & Male & Female & Male & Female \\
\hline Average & 20.51 & 16.54 & 10.24 & 8.53 \\
\hline Std. Dev. & 6.06 & 6.26 & 4.47 & 4.79 \\
\hline $\boldsymbol{n}$ & 271 & 35 & 245 & 30 \\
\hline Significance & \multicolumn{2}{|c|}{$p=0.0002$} & \multicolumn{2}{c|}{$p=0.0257$} \\
\hline
\end{tabular}

Table $\mathrm{V}$ includes the average scores obtained by discipline for the three programs under consideration as well as for other programs of interest. Also included in this table are results obtained using these instruments at various other institutions, including those in the U.S., Poland, and Germany [11]. All of the data presented in Table $\mathrm{V}$ is for first-year students only.

TABLE V. RESUlTS FROM SPATIAL SKILLS TESTING.

\begin{tabular}{|l|c|c|}
\hline DIT Students: & $\begin{array}{c}\text { PSVT:R } \\
(\mathbf{e x . ~ 3 0 )}\end{array}$ & $\begin{array}{c}\text { MCT } \\
(\mathbf{e x . ~ 2 5 )}\end{array}$ \\
\hline DT004 - Civil Eng. (Level 7) & 17.53 & 7.53 \\
\hline DT006 - Mechanical Eng. (Level 7) & 19.51 & 9.84 \\
\hline DT025 - Common Eng. (Level 8) & 21.90 & 11.10 \\
\hline \hline Architecture & 19.94 & 11.59 \\
\hline Architectural Technology & 21.29 & 11.88 \\
\hline Computer Science & 22.19 & 8.41 \\
\hline
\end{tabular}

\begin{tabular}{|l|c|c|}
\hline \multicolumn{1}{|l|}{ Comparable Studies: } & \multicolumn{2}{|}{} \\
\hline U.S. Engineering Students & 24.43 & N/A \\
\hline Polish Engineering Students & N/A & 14.95 \\
\hline German Engineering Students & N/A & 15.93 \\
\hline
\end{tabular}

The following observations can be made from this data:

- The spatial skills of the Irish students appear to be behind those of the students in the U.S. and in other European countries. The reasons behind this merit further investigation with one possible reason for this is that the Irish students tend to be younger when 
compared to first-year students in most other countries. For example, Irish students are typically 17-19; whereas, the students in the U.S. and Poland are generally 18-19 and in Germany 19-20. An alternate explanation for these differences by country lies in participation rates for higher education. Table VI shows the participation rates for the countries included in this comparison. Since Ireland has a significantly higher participation rate in higher education, it stands to reason that the post-secondary entrants would appear to be 'weaker' when compared to the students from Germany who represent only a small, elite fraction of the total population. Other confounding factors such as socio-economic status or ethnicity could also be relevant in this analysis, requiring further investigation in the future.

TABLE VI. PERCENT OF SECONDARy GRAduates who Pursue Higher EDUCATION [12]-[15]

\begin{tabular}{|c|c|c|c|}
\hline Ireland & U.S. & Germany & Poland \\
\hline $84 \%$ & $68 \%$ & $\approx 30 \%$ & $>50 \%$ \\
\hline
\end{tabular}

- The spatial skills of the students in the ordinary programs appear to be lower than those in the honors programs. This is not surprising given that others have found a link between spatial skills and math ability [16] and the students in the honors programs typically have higher math entrance scores.

- For the computer science students, the scores on the rotation test are among the highest and the scores on the cutting test are among the lowest. This could be due to the fact that a large number of computer science students typically play computer games for a significant amount of time. Since most computer games involve rotating objects or people in space and not as much time in determining cross-sections of objects, this could be an explanation for this finding. Computing students are generally attracted to these programs because of an interest that often originates in gaming. Construction-related games such as Minecraft and even shoot-'em-up games have all been shown to improve spatial skills [17].

- Upon initial examination, it appears that the scores for the Architecture students are lower than they are for the other honors programs; however, this is likely due to the relatively large percentage of women in that program $(30 \%)$ compared to the other programs (less than $10 \%$ ). In fact, in the Architectural Technology program, there is not a single first-year female student for whom test scores are available. Table VII shows the gender breakdown for the Architecture students. From this data, it appears that the scores for the males are on par (or better) than those in the other honors programs where men predominate.

\section{First Semester Math Performance}

For the three programs under consideration in this study, a number of variables were examined. Figs 4, 5, and 6 show scatter plots and correlations between LC points and grades earned in the various first-semester mathematics courses completed by the students.

TABLE VII. AVERAGE TEST SCORES By GENDER FOR ARCHITECTURE STUDENTS

\begin{tabular}{|l|c|c|}
\hline DIT Students: & $\begin{array}{c}\text { PSVT:R } \\
(\text { ex. 30) }\end{array}$ & $\begin{array}{c}\text { MCT } \\
(\text { ex. 25) }\end{array}$ \\
\hline Males $(\boldsymbol{n}=\mathbf{2 8})$ & 21.81 & 12.55 \\
\hline Females $(\boldsymbol{n}=\mathbf{1 2})$ & 15.10 & 8.86 \\
\hline
\end{tabular}

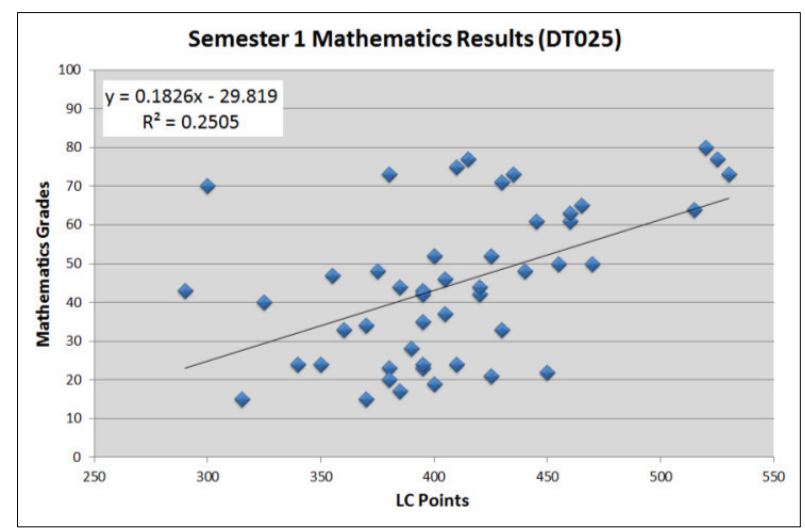

Fig. 4. Scatter Plot For Level 8 Common Engineering Degree

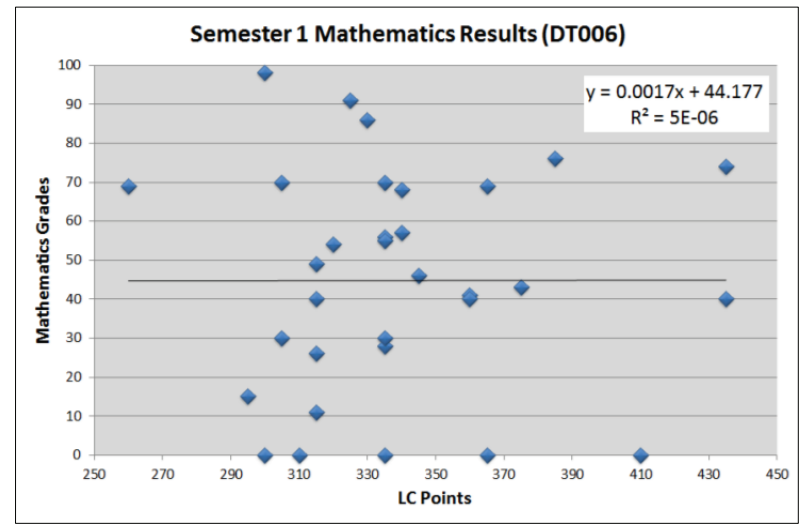

Fig. 5. Scatter Plot For Level 7 Mechanical Engineering Degree.

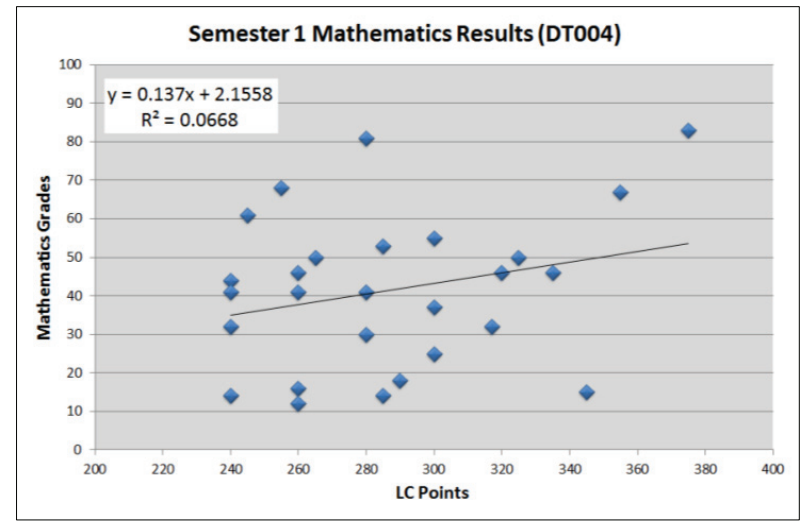

Fig. 6. Scatter Plot For Level 7 Civil Engineering Degree. 
From these figures it can be seen that LC Points are a good predictor of success in higher level mathematics for students in the honors program ( $p<0.0001$ for correlation coefficient), but not for those in the ordinary programs. It could be that the classes at the institute are similar to the classes in the high schools, so similar patterns of success emerge for this group of students. For students in the ordinary degree programs, success in math courses may be tied more closely to affective variables such as motivation rather than ability as measured by LC Points.

In looking at relationships between performance on the MCT and performance in the introductory math course, no significant correlations are found; the correlation for the DT004 program was approaching significance $(r=0.318, p=$ 0.0762 ). However, we also wanted to see if poor spatial skills would lead to poor performance in the math course. For this analysis, we selected a score of 11 out of 25 on the MCT as the cut-off between weak/marginal spatial skills and good spatial skills. In other words, students who scored 11 or lower were pooled into one group ('weak visualizers') with students who scored 12 or higher pooled into another group ('good visualizers'). It should be noted that this cut-off score was based somewhat on data gathered from previous studies in the U.S. which categorized CAD-learners as either weak, average or high visualizers based on their score on the MCT [18].

Further, we defined success in math as receiving a passing grade in the course $(\geq 40 \%)$. By contrast, non-success was defined as either failing the course $(<40 \%)$ or not completing the course. It was assumed that if students were present for the first part of the course when the test was administered and were not present at the end of the semester for the final exam that they had decided against the major. Table VIII includes data regarding math course success rates for students with weak spatial skills compared to those with good spatial skills. Also included in this table are the average grades obtained in the math course for each group as well as the average LC points for the students in the groups.

Note: Even though the differences between the weak visualizers and good visualizers in the Level 7 Civil Engineering program are statistically significant (effect size $=$ 0.83 ), they are not likely meaningful differences. There were only three students in this group who were good visualizers compared to 29 who were weak visualizers. Further, LC points were only available for two of the three students. This very small sample size makes conclusions based on the data tenuous.

The following observations are made from the data presented in Table VIII:

- For the honors students, LC points and not visualization skills appear to predict success in the introductory math course, as we saw from the significant correlations obtained for this group. However, for the students in the ordinary mechanical engineering program, the opposite appears to be the case. For the students in the ordinary program, the students who were not successful in the math course were primarily from the low visualizer group. In fact, only one student who was a good visualizer was not successful in the math course.

- For students in the level 7 Civil Engineering program, both LC points and visualization skills could be predictors of success in the math course (recall that MCT score and LC points were weakly correlated for this group). Since there were only three students in the good visualizer group for this program it is difficult to draw meaningful conclusions from the data. One additional issue for this group of students is the fact that the spatial tests were administered during the spring semester and not the fall. It could be that there were other students in both the strong and weak groups that dropped out prior to the start of the semester.

TABLE VIII. SUCCESS RATE AND AVERAGE SCORES FOR STUDENTS

\begin{tabular}{|c|c|c|c|}
\hline & & $\begin{array}{c}\text { Weak } \\
\text { Visualizers }\end{array}$ & $\begin{array}{c}\text { Good } \\
\text { Visualizers }\end{array}$ \\
\hline \multirow{3}{*}{$\begin{array}{l}\text { Common } \\
\text { Engineering } \\
\text { (Level 8) }\end{array}$} & Success Rate & $26 / 43=60.5 \%$ & $21 / 35=60.5 \%$ \\
\hline & $\begin{array}{l}\text { Average } \\
\text { Math Score }\end{array}$ & 49.4 & 46.8 \\
\hline & $\begin{array}{l}\text { Average } \\
\text { LC Score }\end{array}$ & $395.8^{*}$ & 420.5 \\
\hline \multirow{3}{*}{$\begin{array}{c}\text { Mechanical } \\
\text { Engineering } \\
\text { (Level 7) }\end{array}$} & Success Rate & $19 / 29=65.5 \%$ & $14 / 15=93.3 \%$ \\
\hline & $\begin{array}{l}\text { Average } \\
\text { Math Score }\end{array}$ & $49.9 \%$ & $62.9 \%$ \\
\hline & $\begin{array}{l}\text { Average } \\
\text { LC Score }\end{array}$ & 330.2 & 347.5 \\
\hline \multirow{3}{*}{$\begin{array}{c}\text { Civil } \\
\text { Engineering } \\
\text { (Level 7) }\end{array}$} & Success Rate & $16 / 29=52.2 \% * *$ & $26 / 43=60.5 \%$ \\
\hline & $\begin{array}{l}\text { Average } \\
\text { Math Score }\end{array}$ & $38.36^{*}$ & 63.33 \\
\hline & $\begin{array}{l}\text { Average } \\
\text { LC Score }\end{array}$ & $280.3 *$ & 365.0 \\
\hline
\end{tabular}

* Difference between two groups significant at $p<0.05$

** Difference between two groups approaching significance at $p<0.1$

- The high failure rate in the honors degree program came as a surprise and could be indicative of the perception by students, whether true or not, that the contents of the math course in the first semester was the same as materials that had been covered in secondary level honors math courses. Students who perceive this to be the case frequently do not engage with the math course because they believe that they will pass without any extra effort as a result of previous successes. However, differences in assessment, particularly where continuous assessment is used as well as summative, end-of-semester exams, often lead to poor performances by students. Also, although some of the subject matter may be similar on the syllabi for the secondary and college-level math courses, the style and level of assessment may be quite different and a lack of engagement, particularly in 
relation to tutorials, may leave students unprepared. Furthermore, students who initially are not successful in the math course are allowed to repeat the exam over the summer months. The reassessment performance (end of stage repeat assessments) of these students will again be correlated against their LC points. Based on previous LC performance, it would be predicted that most of the students from this group who take the reassessment would pass the second time.

- Sample sizes with regards to gender and ethnicity from this study were too small to analyze if these were also factors in student success. This is something that merits further investigation.

\section{DISCUSSION}

For students with greater than 450 LC points, i.e. with an average mark of approximately $70 \%$ per leaving cert higher level subject, there is clear correlation between LC performance and first semester math results suggesting that:

- The materials covered during the semester may be a repeat of or only build slightly upon content also covered on the LC syllabus.

- The style of delivery of materials and learning by the students is the same in both cases. However, these students obviously also applied themselves to the module and partook fully in all required assessment elements.

From 350 to 450 points (54\%-70\% higher level averages) significant differences appear between the performances of students on the honors and ordinary level programs. With the exception of two students who did not take the end of semester assessment, all students in this group from both level 7 Mechanical and Civil programs passed the module. For the level 8 Common Engineering program only $56 \%$ of the students in this group achieved grades above $40 \%$.

Students with LC points below 350 (averages below 54\% at higher level) on both level 7 and level 8 degree programs are almost as likely to fail the first semester math module as pass it. As with the 350-450 honors degree group, this could be indicative of a lack of engagement with the module and corresponding poor assessment performance. However, the reasons for lack of engagement with the module are more likely to relate to a corresponding submersion in the college experience. This suggestion can only be verified by dialogue with the students who did not succeed in the module. Again with this group, reassessment performance will be compared with LC results in future work and attendance records will be analyzed.

\section{CONCLUSIONS}

It appears that for students with strong preparation in mathematics, their secondary learning prepares them well for introductory math courses on engineering programs. In this case, prior performance is an indicator of future successes. For students with lower levels of math preparation, however, there is no correlation between preparation and performance. For this group, other factors such as motivation are likely to be a predictor of success. In previous studies conducted in the U.S., it was found that spatial skills predict grades and persistence in engineering programs. In other words, students who had higher levels of spatial skills graduated from engineering at higher rates when compared to students with low spatial skills. Interventions designed to help students improve their spatial skills were effective in ensuring that these students persisted in and graduated from engineering.

In this study, it is too early to tell whether or not spatial skills will predict persistence or attrition. For the future, we plan to track these students to determine long-term outcomes for weak and good visualizers. Future research may also include the conduct of an intervention study to determine if this will have a positive impact on student persistence in engineering and an examination of other possible contributory factors such as gender or national origin.

\section{REFERENCES}

[1] Tartre, L.A. 1990. Spatial skills, gender, and mathematics. In E. H. Fennema \& G. C. Leder (Eds.), Mathematics and Gender, (pp. 27-59). New York, NY: Teachers College Press.J. Clerk Maxwell, A Treatise on Electricity and Magnetism, 3rd ed., Vol. 2. Oxford: Clarendon, 1892, pp.68-73.

[2] Sorby, S. and Gorska, R. A. 1998. The Effect of Various Courses and Teaching Methods on the Improvement of Spatial Ability. Proceedings of the 8th International Conference on Engineering Design Graphics and Descriptive Geometry, Austin, TX, July 1998, pp.252-256.

[3] Linn, M.C., and Petersen, A.C. 1985. Emergence and characterization of sex differences in spatial ability: A meta-analysis. Child Development Vol. 56, pp. 1479-1498.

[4] CEEB Special Aptitude Test in Spatial Relations, developed by the College Entrance Examination Board, USA, 1939.

[5] Guay, R. B. 1977. Purdue spatial visualization test: Rotations. West Lafayette, In, Purdue Research Foundation.

[6] Higher Education Authority (HEA), April 30, 2013. Higher Education Key Facts \& Figures 2011/12.

http://www.hea.ie/en/publications/2013 Accessed: 11 April 2014

[7] Higher Education Authority (HEA), 2013. An Analysis of CAO First Preference Applications 2013. http://www.hea.ie/en/publications/2013 Accessed: 11 April 2014

[8] Voyer, D., Voyer, S., \& Bryden, M. 1995. Magnitude of sex differences in spatial abilities: A meta-analysis and consideration of critical variables. Psychological BulletinVol. 117(2): pp. 250-270.

[9] Wai, J., Lubinski, D., \& Benbow, C. P. 2009. Spatial ability for STEM domains: Aligning over 50 years of cumulative psychological knowledge solidifies its importance. Journal of Educational Psychology, Vol. 101(4), pp. 817-835.

[10] Sorby, S. A. (2001). "A Course in Spatial Visualization and its Impact on the Retention of Women Engineering Students," S. A. Sorby, Journal of Women and Minorities in Science and Engineering, Vol. 7, No. 2, 2001, pp.153-172.

[11] Sorby, S., Leopols, C., and Goeska, R. "Cross-Cultural Comparisons of Gender Differences in the Spatial Skills of Engineering Students". Journal of Women and Minorities in Science and Engineering, Vol. 5, No. 3, 1999, pp. 279-291.

[12] "College Participation - Ireland" http://www.thejournal.ie/fewer-students-to-sit-this-years-leaving-cert470967-Jun2012/ Accessed: 15 April 2014

[13] "College Participation - U.S." http://nces.ed.gov/fastfacts/display.asp?id=372 Accessed: 15 April 2014

[14] "College Participation - Poland" (http://gse.buffalo.edu/org/inthigheredfinance/files/Country_Profiles/Eur ope/Poland.pdf Accessed: 15 April 2014 
[15] "College Participation - Germany" http://www.german-way.com/history-and-culture/education/2013 Accessed: 15 April 2014

[16] Fennema, E., \& Sherman, J.A. (1977). Sexual stereotyping and mathematics learning. The Arithmetic Teacher, Vol. 24(5), pp. 369-372.

[17] Green, C., \& Bavelier, D. (2003). Action video game modifies visual selective attention. Nature, Vol.423(6939), p.534.
[18] Hamlin, A. J., Boersma, N. and Sorby, S. A., "Do Spatial Abilities Impact the Learning of 3-D Modeling Software?" Proceedings of the 2006 Annual Conference of the American Society for Engineering Education, Chicago, Illinois, June 2006, CD-ROM. 